\title{
FENOLOGÍA REPRODUCTIVA DE Myrciaria dubia McVAUGH (H.B.K.) CAMU CAMU
}

\section{Herminio Inga*, Mario Pinedo*, César Delgado ${ }^{* *}$, Carlos Linares*, Kember Mejía*}

\section{RESUMEN}

El camu camu es un frutal arbustivo que crece en las riberas inundables de ciertos ríos y lagos de la Amazonía baja formando poblaciones naturales densas. El presente trabajo fue desarrollado en las poblaciones naturales de las cochas Sahua y Supay en el río Ucayali, distrito de Jenaro Herrera ( $\left.73^{\circ} 40^{\prime} \mathrm{O}, 4^{\circ} 55^{\prime} \mathrm{S}\right)$, provincia de Requena, departamento de Loreto. Para estudiar la fenología reproductiva, fueron seleccionadas y marcadas cinco plantas por cada población con el objetivo de estudiar el desarrollo fenológico reproductivo de la especie.

El periodo evaluado se inició con la diferenciación de la yema floral y concluyó con la maduración del fruto, que comprende 2 estados y 12 fases de una duración aproximada de 77 días. El estado de floración abarca 4 fases y dura 15 días, mientras que el estado de fructificación ha sido dividido en 8 fases de una duración de 62 días.

Se evaluó la fertilidad efectiva de las flores y se encontró que el $27 \%$ de las flores fertilizadas llega a formar frutos maduros.

Palabras clave: Fenología reproductiva, fertilidad, camu camu, Myrtaceae.

\section{ABSTRACT}

Camu camu (Myrciaria dubia, Myrtaceae) is a fruit-bearing shrub, which grows on the floodplains along the rivers in the Amazon lowlands. This area has the largest wild populations of this species in South America. The present study was performed with wild populations from the Sahua and Supay lakes, on the Ucayali River in the District of Jenaro Herrera. Requena Province, Department of Loreto, Peru. To study

\footnotetext{
* Instituto de Investigaciones de la Amazonía Peruana. Programa de Ecosistemas Terrestres. Avda. Abelardo Quiñones Km 2,5, Iquitos (Perú). Correo electrónico: pet@iiap.org.pe

** Instituto de Investigaciones de la Amazonía Peruana. Programa de Biodiversidad. Avda. Abelardo Quiñones Km 2,5, Iquitos (Perú). Correo electrónico: pbio@iiap.org.pe
} 
the reproductive phenology, five plants from each population were selected and marked. The observation period began with the differentiation of the floral bud and continued until the development of mature fruit that included two states, flowering and fruiting, and 12 phases of development with a total duration of 77 days. The flowering period included 4 phases and lasted 15 days while the fruiting period included 8 phases and lasted 62 days.

We also measured the effective fertility, and from the harvest found that $27 \%$ of fertilized flowers formed mature fruit.

Key words: Reproductive phenology, fertility, camu camu, Myrtaceae.

\section{INTRODUCCIÓN}

Myrciaria dubia, Myrtaceae, es un frutal silvestre de la Amazonía. Crece en las riberas inundables de los ríos y cochas de aguas oscuras y puede permanecer completamente sumergido en agua durante cuatro o cinco meses (Peters y Vásquez, 1986).

Se la encuentra en las riberas de los ríos Solimoes (Amazonas), Negro, Trombetas, Xingu, Tocantines, Madeira, Tapajos, Acre, Yavari, Macangana y Urupé, en el Brasil; Amazonas, Ucayali, Marañón, Napo, Tigre, Curaray, Yavarí y Tahuayo, en el Perú; Putumayo e Inírida, en Colombia; así como también en la cuenca superior del Orinoco, en Venezuela. La mayor concentración y diversidad de las poblaciones se encuentra en la Amazonía Peruana (Peters y Vásquez, 1986; Chávez, 1993; SEBRAE, 1995).

El alto contenido de ácido ascórbico de los frutos, cuyos valores se encuentran entre los 2000 y los $2994 \mathrm{mg} / 100 \mathrm{~g}$ de pulpa fresca (Ferreyra, 1959; Roca, 1965) ha despertado gran interés en el mercado mundial, dentro del cual Japón, Francia y Estados Unidos son los principales importadores (Weiss, 1998).

\section{ANTECEDENTES}

Las plantas de camu camu inician la floración cuando alcanzan un diámetro basal de $2,0 \mathrm{~cm}$, que corresponde a los arbustos que tienen entre dos y tres años de edad aproximadamente. 
La floración de un individuo ocurre en forma continua. Las yemas florales emergen desde las ramas superiores hacia las ramas inferiores. Por lo tanto, un individuo puede presentar yemas florales, flores y frutos en varios estados de desarrollo al mismo tiempo (Peters y Vásquez, 1986).

La inflorescencia es axilar. Las flores, agrupadas de una a doce, son subsésiles y hermafroditas. El cáliz tiene cuatro lóbulos ovoides y la corola, cuatro pétalos blancos. El ovario es ínfero, androceo y cuenta con 125 estambres. La fecundación ocurre por alogamia facultativa y la polinización es realizada por la acción del viento o de los insectos (Peters y Vásquez, 1986; Barriga, 1994; Villachica, 1996 y Flores, 1997).

\section{MATERIALES Y MÉTODOS}

El presente trabajo fue realizado entre setiembre y diciembre de 1999 en las poblaciones naturales de las cochas Sahua y Supay, lagos fluviales del río Ucayali, distrito de Jenaro Herrera, provincia de Requena, departamento de Loreto, a $6 \mathrm{~km}$ de la Villa Jenaro Herrera $\left(73^{\circ} 40^{\prime} \mathrm{O}, 4^{\circ} 55^{\prime} \mathrm{S}\right)$.

Las poblaciones de camu camu ocupan una extensión aproximada de 40 ha y son influenciadas por las aguas del río Ucayali en la época de máxima creciente.

Se seleccionaron cinco plantas de la cocha Sahua y cinco plantas en la cocha Supay. En cada una de ellas, fueron marcadas tres ramas elegidas al azar. Las evaluaciones se realizaron cada tres días hasta la completa madurez del fruto.

\section{RESULTADOS Y DISCUSIÓN}

Se han considerado dos estados: uno de desarrollo de la flor, que comprende cuatro fases, y otro de desarrollo del fruto, que comprende ocho fases.

El ciclo total de fenología reproductiva del camu camu ocurrió en 77 días, de los cuales 62 corresponden a la formación y maduración del fruto (Figura 1).

Las flores que logran llegar a la última fase de fruto maduro constituyen el $27 \%$ (Figura 2) del total de flores fecundadas. 


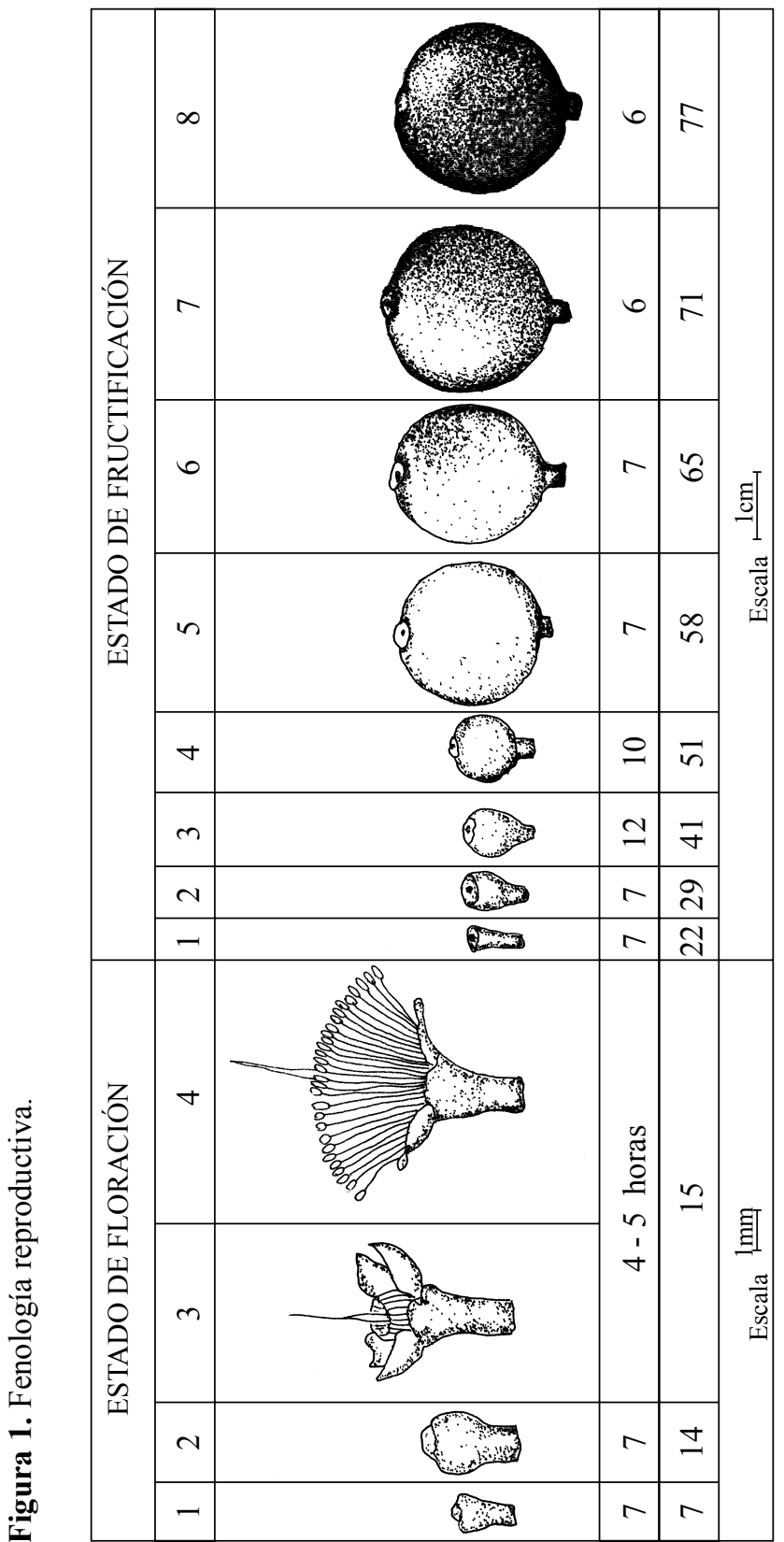




\section{Estado I: Desarrollo de la flor}

El desarrollo de la flor involucra cuatro fases:

Fase 1. Desde la aparición de la yema floral y los siete días subsiguientes.

Fase 2. La yema floral experimenta un crecimiento en su longitud y diámetro hasta presentar una forma parecida a la de un globo. Esta fase comprende siete días.

Fase 3. El botón floral se abre y emerge primero el estilo. Luego, por la mañana, emergen los estambres. En este momento, la flor queda polinizada y se observa la presencia de abejas (Melipona fuscopilara y Trigona italica).

Fase 4. Una vez que el estilo emerge y es polinizado, empiezan a desprenderse los estambres de la flor. Las fases 3 y 4 comprenden entre cuatro y cinco horas. Desde la aparición de la yema floral hasta el inicio de la formación del fruto transcurren 15 días.

\section{Estado II: Desarrollo del fruto}

Luego de la fecundación, el proceso de fructificación transcurre durante ocho fases:

Fase 1. Una vez fecundada la flor, los estambres y los sépalos se desprenden. El estilo adopta la forma de un clavito de color verde claro que mide $0,15 \mathrm{~cm}$ de altura. Esta fase comprende siete días.

Fase 2. El fruto que tenía la forma de un clavito continúa su desarrollo y adopta una coloración verde oscura. Llega a medir entre 0,16 y $0,35 \mathrm{~cm}$ de largo. Esta fase comprende también siete días.

Fase 3. Se observa que el fruto aumenta su tamaño. Su coloración permanece verde y llega a medir entre 0,36 y $0,60 \mathrm{~cm}$. Esta fase comprende 12 días.

Fase 4. El fruto mantiene su color verde. Mide entre 0,61 y 1,0 cm de diámetro. A partir de esta fase, que dura 10 días, los frutos son considerados fisiológicamente desarrollados.

Fase 5. En esta fase, cuya duración es de siete días, el fruto llega a medir 2,4 cm de diámetro y a tener un peso promedio de $7,5 \mathrm{~g}$.

Fase 6. El fruto presenta pequeñas manchas rojizas. Por ello, se le denomina «verdepintón». Asimismo, mide 2,5 cm de diámetro y su peso es de 9,3 g en promedio. Esta fase comprende un periodo de siete días.

Fase 7. El fruto presenta un color verde rojizo: rojo claro con manchas verdes. Se le denomina «pintón-maduro». Mide 2,6 cm de diámetro y pesa 10,3 g en promedio. Esta fase comprende seis días. 
Fase 8. El fruto, en su totalidad, es de color rojo vino. Se le considera un fruto maduro. Mide $2,5 \mathrm{~cm}$ de diámetro y pesa $10 \mathrm{~g}$ en promedio. Esta fase comprende seis días.

Según Vásquez (2000), desde la aparición de los primeros brotes floríferos a manera de cabeza de alfiler y el proceso mismo de maduración de la fruta, transcurren 56 días. En el presente estudio, hemos encontrado que este lapso es de 77 días. La diferencia podría ser explicada por las influencias ambientales y genéticas.

(Peters y Vásquez, 1986) determinaron 39,5\% de persistencia de los frutos de camu camu. Después de 19 años, en el mismo sitio, se encontró un valor de 27\% (Figura 2), lo que podría ser atribuido al tamaño de la muestra y a las variaciones ambientales.

Figura 2. Fertilidad efectiva de flores desde su formación hasta la madurez del fruto.

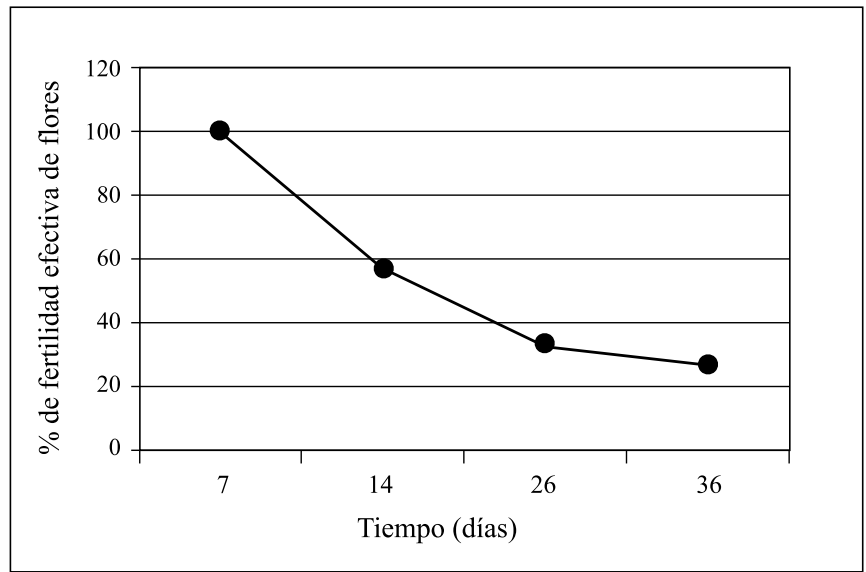

\section{CONCLUSIONES}

- La fenología reproductiva del camu camu transcurrió en 77 días. Estos son divisibles en dos periodos: uno de desarrollo de la flor, que comprende cuatro fases, y el otro de desarrollo del fruto, que comprende ocho fases. 
- La floración dura 15 días; el desarrollo del fruto, que comprende el lapso que va desde la caída de los estambres y sépalos hasta que el fruto esté fisiológicamente desarrollado, tarda 36 días. La maduración del fruto transcurre en 26 días.

- La fertilidad efectiva de las flores que logran producir frutos maduros es de $27 \%$.

\section{BIBLIOGRAFÍA}

BARRIGA, R. 1994. Plantas Útiles de la Amazonía Peruana: Características, Usos y Posibilidades. Lima (Perú): CONCYTEC. pp 80 - 84.

CALZADA B. J. 1978. El Camu Camu (Myrciaria paraensis), Frutal nativo de mucha importancia. Lima (Perú): Universidad Nacional Agraria La Molina. 11 pp. (mimeografiado).

CHÁVEZ, W. 1993. Camu camu. En: Clay, C.W.; Clement, C.R. (ed.). Selected especies and strategies to enhance income generation from Amazonian forest FO: Misc.93/6. Working Paper. Rome: FAO. pp. 39 -146.

FERREYRA, R. 1959. Camu camu, nueva fuente nacional de vitamina C. En: Bol. Exp. Agropecuaria 7(4): 28.

FLORES, S. 1997. Cultivo de Frutales Nativos Amazónicos. Manual para el Extensionista. En: Tratado de Cooperación Amazónica. Lima (Perú): Secretaría Pro Tempore. pp. 55-62.

PETERS, CH.; VÁSQUEZ, A. 1986. Estudios Ecológicos de Camu camu Myrciaria dubia. I. Producción de Frutos en Poblaciones Naturales. En: Acta Amazónica 16 -17 (Número único). Brasil. pp. 161-174.

ROCA, N. A. 1965. Estudio químico-bromatológico de la Myrciaria paraensis Berg. Lima: Universidad Nacional Mayor de San Marcos. Tesis de Química. 51pp.

SERVICIO DE APOIO AS MICRO E PEQUENAS EMPRESAS DO ACRE (SEBRAE). 1995. Caтu camu: opcoes de investimento no Acre con produtos florestais nao madeireiros. Río Branco (Brasil): SEBRAE. 28 pp. 
VÁSQUEZ, A. 2000. El Camu Camu. Cultivo, Manejo e Investigaciones. Iquitos (Perú): Editora Gráfica e Imprenta Universal S.R.L. 218 pp.

VILLACHICA, H. 1996. Frutales y Hortalizas Promisorios de la Amazonía. En: Tratado de Cooperación Amazónica. Lima (Perú): Secretaría Pro Tempore. 76-83 pp.

WEISS, D. K. 1998. Un estudio del mercado mundial para Camu camu. Winrock International. Proyecto de Desarrollo Alternativo USAID/CONTRADROGAS. Convenio USAID - INADE. 18 pp. 